\title{
A Contabilidade Gerencial e os Métodos Multicriteriais
}

\author{
Rodney Wernke \\ Contador, Professor de Custos/UNISUL \\ Mestre e Doutorando em Engenharia de \\ Produção/UFSC
}

RESUMO

Os métodos multicritérios agregam um valor significativo à informação contábil, na medida em que não somente permitem a abordagem de problemas considerados complexos e, por isto mesmo, não tratáveis pelos procedimentos intuitivo-empíricos usuais, mas também conferem, ao processo de tomada de decisão uma clareza e conseqüente transparência não disponíveis quando esses procedimentos, ou outros métodos de natureza monocritério, são utilizados. Discorre-se acerca dos métodos multicriteriais de apoio à tomada de decisão, citando conceitos e referências históricas, abordando medidas subjetivas e seu uso pela contabilidade gerencial, apresentando os principais métodos multiatributos de apoio à tomada de decisão e alguns casos de aplicação na área contábil.

Palavras-chave: Informações Gerenciais, Métodos Multicriteriais, Subjetividade.

\section{Antonio Cezar Bornia \\ Professor do PPGEP/UFSC \\ Doutor em Engenharia de Produção/UFSC}

ABSTRACT

Multicriterion methods aggregate a significant value to accounting information, since they do not only allow for the treatment of problems that are considered complex and that, therefore, cannot be treated by the usual intuitive-empirical procedures, but also provide the decision-making process with a level of clearness and, consequently, transparency that is not available when these procedures or other monocriterion methods are used. This article deals with the multicriterion methods that support decisionmaking, quoting concepts and historical references, discussing subjective measures and their use in management accounting and presenting the main multi-attribute methods used in support of decisionmaking and some examples of their application in the accounting area.

Key words: Management Information, Multicriterion Methods, Subjectivity. 


\section{1 - INTRODUÇÃO}

Apesar de o objetivo das atuais informações contábeis ser o de subsidiar os gerentes, no aprimoramento da eficiência e eficácia de suas operações, conforme Ostrenga et alii (1993, p. 22), algumas vezes elas têm surtido efeito exatamente oposto. Como a dinâmica dos custos freqüentemente não é bem retratada, as informações sobre o desempenho, fornecidas pelos atuais sistemas de contabilidade gerencial, são, na melhor das hipóteses, incompletas.

Tal deficiência se torna mais evidente no caso dos ativos intangíveis. Neste sentido, Sveiby (1998, p. 186) diz que é tentadora a intenção de criar-se um sistema de avaliação de intangíveis equivalente à contabilidade da partida dobrada, tendo o dinheiro como denominador comum. É uma estrutura consagrada com definições e padrões e, por isso, representativa do consenso geral. Mas essa é exatamente a razão pela qual deve ser eliminada, pois, se avaliarmos o novo com as ferramentas do antigo, não teremos como perceber o novo. Sveiby afirma ainda que qualquer sistema de avaliação é limitado pelo princípio da incerteza de Heisenberg, segundo o qual é impossível medir simultaneamente a velocidade e a posição das partículas e, segundo o físico Niels Bohr, isso significa que o observador está sempre envolvido na avaliação e que o mundo físico não possui atributos bem definidos.

A subjetividade mencionada tem implicações contábeis relevantes. Reis \& Guerreiro (1999, p.16) argúem que o gestor envolvido com decisões cotidianas da empresa requer informações que o auxiliem na escolha de alternativas otimizadoras. Nesse caso, é perceptível a importância da utilização de conceitos subjetivos. As decisões ótimas são aquelas que elevam o valor da empresa e o administrador necessita conhecer o impacto de cada decisão sobre o valor da empresa, ainda que de maneira subjetiva, pois este representa a 'verdade relativa' do instante da decisão.

Quanto à forma de abordagem do processo de decisão, no contexto empresarial, segundo Borgert (1999, p. 74), verifica-se uma crescente orientação para a utilização de instrumentos analíticos baseados numa perspectiva multidimensional. Quer relativamente aos problemas de avaliação do grau de desempenho das empresas (isto é, da sua competitividade global), quer no domínio da gestão contábil, o processo de tomada de decisão é, com efeito, função de uma multiplicidade de dimensões ou critérios de avaliação.

Neste sentido, Diehl (1997, p. 38) considera que, ao se defrontar com algum problema, normalmente leva-se em conta não só um tipo de critério para a decisão, mas uma multiplicidade de fatores. Cita como exemplo que, ao decidir sobre a realização ou não de horas-extras, um executivo irá considerar não só o custo adicional associado, mas também o lucro a ser auferido, possíveis complicações sindicais e outros fatores. Esta análise multi-atributos estabelece uma forma estruturada de julgamento acerca de diversos atributos de decisão. Ou seja, ela permite ordenar as alternativas segundo certos critérios de decisão, seguindo uma ótica própria. Isto pode ser feito de diversas formas: atribuindo pesos aos atributos, estabelecendo uma relação ordinal ou cardinal entre eles, através de visualização, etc.

Este tópico discorre, então, acerca dos métodos multicriteriais de apoio à tomada de decisão focalizados por meio de uma revisão bibliográfica acerca de conceitos pertinentes, das referências históricas, da necessidade de medidas não-financeiras e seu uso pela contabilidade gerencial e finaliza comentando os principais métodos multicriteriais de apoio à tomada de decisão.

\section{2 - CONCEITUAÇÃO E HISTÓRICO}

Gomes \& Freitas Jr. (2000, p. 83) registram que até a primeira metade do século XX abordavam-se os processos complexos de tomada de decisão utilizando basicamente matemática para as decisões, em condições consideradas aleatórias, com grandes limitações e riscos associados. Na década de 50, em função de experiências realizadas pelas Forças Aliadas na abordagem dos problemas logísticomilitares surgidos durante a $2^{a}$ Guerra Mundial, ganhou ênfase a solução de problemas empregandose a então nascente Pesquisa Operacional. $\mathrm{Na}$ década de 60 surgiram métodos probabilísticos, voltados para a tomada de decisão, que foram aplicados em diversos trabalhos técnicos, desenvolvidos até a década passada. Já nos anos 70 , surgem os primeiros métodos voltados para os problemas discretos de decisão, no ambiente multicritério, ou seja, métodos que utilizam uma abordagem diferenciada para essa classe de 
problemas e que passam a atuar sob a forma de auxílio à decisão, não só visando à representação multidimensional dos problemas, mas também incorporando um conjunto de características bem definidas quanto a sua metodologia.

Diehl (1999, p. 13) relata que há bastante tempo os métodos multicriteriais (também conhecidos na literatura como Métodos Multi-atributos ou Multi-objetivos) são, formal ou informalmente, utilizados. Como exemplo disso, tal autor cita a obra de Canada e Sullivan ${ }^{1}$, em que consta uma carta de Benjamin Franklin, enviada a seu amigo Joseph Priestly, datada de 1772, na qual ele ensina um método simples de consideração de vários atributos para um processo de decisão. Nas décadas de 70 e 80 , houve o surgimento de várias técnicas novas de avaliação por multicritérios que ajudam os administradores a decidirem de forma eficaz em relação a custos, e também como uma forma de avaliar riscos e desempenho quando da análise de alternativas de investimento.

Conforme Costa (1999, p.2), a partir da década de 70, a eficiência dos modelos ortodoxos de Pesquisa Operacional, em análises de problemas gerenciais complexos, começou a ser questionada. Por isso, nas duas décadas seguintes, passa-se a considerar que não mais se deva analisar problemas procurando uma solução ótima, e sim gerar projetos e soluções de compromisso que permitam ultrapassar a confusão que cerca as situações problemáticas no contexto empresarial. Ou seja, passar do paradigma da otimização para as chamadas soluções de aprendizado e construtivismo. Entre as abordagens que surgiram em resposta a estas questões, talvez as mais importantes sejam as Metodologias Multicritérios de Apoio à Decisão. Tais metodologias apresentam conceitos e bases para estruturar e modelar uma situação problemática, além de incluir maneiras de identificar e gerar ações técnicas para a construção de critérios que possam apontar uma ou mais soluções. Ou seja, a utilização de uma Metodologia Multicritério é bastante interessante em problemas complexos, onde existam diversos tipos de decisores e cada um com vários pontos de vista que considera fundamentais no processo decisório, possuindo muitas vezes objetivos conflitantes e de difícil mensuração, além de, em muitos casos, utilizar variáveis de ordem qualitativa.
Diehl (1997, p.38) menciona que a análise de multiatributos não apresenta uma solução ótima para um dado problema, mas a mais coerente com a escala de valores e com o método utilizado. Trata-se de uma tentativa de racionalização de atributos muitas vezes subjetivos, o que não significa que somente este tipo seja abordado. Dessa forma, em uma análise de multiatributos, o decisor terá que escolher o método de análise ou de ponderação, os atributos pertinentes e sua escala de valores.

Conforme Casarotto \& Kopittke (1998, p. 277), as decisões que envolvem altos valores e prazos longos normalmente comportam:

1. racionalidade limitada: não há curso predeterminado para a escolha da alternativa. Existirão limites de conhecimento e ocorrerá uma forte base de caráter qualitativo como critério;

2. multicritério: uma variedade de objetivos e políticas de caráter qualitativo ou quantitativo nortearão a decisão;

3. multidecisor: embora em pequenas empresas possa haver um único decisor, o normal é a decisão por meio de conselhos;

4. incerteza: as variáveis envolvidas relacionamse aos ambientes cultural, político, econômico e tecnológico, praticamente descartando-se até a possibilidade de se trabalhar com riscos, para se trabalhar com a incerteza.

Gomes \& Freitas Jr. (2000, p.84) ressaltam que a abordagem do problema de decisão, sob o enfoque do Apoio Multicritério à Decisão, não visa apresentar aos decisores solução única ao problema, elegendo uma verdade, que seria representada pela ação selecionada. Objetiva apoiar o processo decisório, através da recomendação de ações ou cursos de ações, a quem vai decidir. Se a qualidade da informação disponível, ao longo do processo de resolução de um problema complexo, é de inquestionável importância, também o é a forma de tratamento analítico daquela mesma informação. Essa forma deve fundamentalmente agregar valor àquela qualidade da informação, havendo, por conseguinte, uma perfeita simbiose entre a qualidade da informação e a qualidade do apoio à tomada de decisão.

Em virtude da complexidade oriunda dos diversos

\footnotetext{
${ }^{1}$ CANADA, J. R. and SULLIVAN, W. G. Economic and multiatributte evaluation of advanced manufacturing systems. Englewood Cliffs: Prentice-Hall, 1989.
} 
fatores componentes do ambiente empresarial moderno, surge na contabilidade a necessidade do uso de medidas não-financeiras, conforme se comenta na seqüência.

\section{3 - A NECESSIDADE DE MEDIDAS NÃO-FINANCEIRAS NA CONTABILIDADE}

A Contabilidade tem se notabilizado por preferir usar critérios objetivos em seus procedimentos, em vez de critérios subjetivos, seguindo o preceituado pela Convenção da Objetividade, que expressa a necessidade de a informação contábil fundamentarse em fatos passados, materializados em transações ocorridas, se possível documentados e mensurados de maneira impessoal. Por exemplo, a mensuração de um ativo, à luz da objetividade, privilegia o custo de aquisição (Reis \& Guerreiro, 1999, p. 3). A subjetividade, em termos contábeis, constitui um conceito que considera as expectativas e percepções pessoais dos agentes econômicos, na identificação e mensuração dos eventos a serem informados pela contabilidade. Neste caso, a mensuração de um ativo deve considerar, à luz da subjetividade, a melhor expressão de seu valor, em um contexto determinado, independentemente de condições objetivas. Em outros termos, a avaliação de um maquinário adquirido para uso produtivo deve considerar o seu fluxo de benefícios futuros.

Atkinson et alii (2000, p. 36) comentam que a informação gerencial contábil tem sido financeira, isto é, tem sido especificada em moedas. Entretanto, recentemente, a informação gerencial contábil foi ampliando-se para incluir informações operacionais ou físicas (não-financeiras), tais como qualidade e tempo de processamento, tanto quanto informações mais subjetivas, como o nível de satisfação dos clientes, a capacitação dos funcionários ou o desempenho do novo produto.

Borgert (1999, p. 49) salienta que as principais críticas à Contabilidade Gerencial relacionam-se ao fato de que esta não oferece subsídios para a tomada de decisão, quando existe a necessidade de extrapolação das questões financeiras. Em função disso, cresce o número de defensores para o uso de múltiplos indicadores de desempenho, no ambiente empresarial.

Neste sentido, Johnson \& Kaplan (1993, p. 222) consideram que, mais importante do que tentar apurar lucros periódicos, é calcular e informar uma variedade de indicadores não-financeiros, mencionando que os indicadores devem se basear na estratégia da companhia, e incluir parâmetros, chave de sucesso, na fabricação, comercialização e P\&D (pesquisa e desenvolvimento). Exemplificam tal raciocínio dizendo que uma companhia que prioriza a qualidade poderia apurar parâmetros internos de falhas (refugos, reparos, índice de peças defeituosas por milhão etc.) e também externos (reclamações de consumidores, gastos com garantia e manutenção). Já as empresas que objetivam competir a custos mais baixos poderão desenvolver indicadores de produtividade, exibindo a tendência de sua capacidade de produzir mais com menos recursos.

Assim, a questão que se coloca é: para as finalidades da Contabilidade Gerencial, a utilização de conceitos subjetivos não deveria prevalecer sobre a objetividade?

Sveiby (1998, p.186) argumenta que, se no mundo físico a verdade está nos olhos de quem a vê, quanto mais no mundo dos negócios. Não existe diferença entre as medidas financeiras e as demais, pois ambas são incertas e dependem do observador. Não existem medidas objetivas. As principais razões pelas quais as medidas financeiras parecem mais objetivas ou "reais" é que elas são encontradas em conceitos implícitos do que é uma empresa e existem há tanto tempo que são regidas por definições e padrões. Após selecionadas, as medidas influenciam o que vemos e a maneira como agimos. O problema, com a tradução de ações em dinheiro, é que muito poucas pessoas em uma organização lidam diretamente com dinheiro. A maioria trabalha utilizando suas competências no serviço aos clientes. O dinheiro é apenas uma procuração para o esforço humano, e o sistema contábil de quinhentos anos oferece poucas contribuições para os processos vitais de organizações cujos ativos são, em grande parte, intangíveis ou não-financeiros. Contudo, não existe um sistema abrangente de avaliação de ativos intangíveis, que utilize o dinheiro como denominador comum e, ao mesmo tempo, seja prático e útil para os gerentes. Dependendo da finalidade da avaliação, segundo tal autor, talvez não seja necessário um sistema, pois os fluxos de conhecimento e os ativos intangíveis são essencialmente não-financeiros.

Diehl (1999, p. 13) menciona que a avaliação de 
aspectos intangíveis em um processo de tomada de decisão transcende os fatores ditos objetivos. Em muitos casos, a importância dos aspectos intangíveis é mesmo maior que a dos aspectos tangíveis. Nessas situações, o uso de métodos que permitam a incorporação de diversos atributos e sua conveniente consideração passa a ser uma necessidade. Os métodos multicriteriais, usados nos processos de decisão, apresentam a possibilidade da consideração não só de medidas objetivas mas também de medidas subjetivas. Conforme a circunstância encontrada, pode ser recomendado (ou não) o uso de um método multicriterial. Desde os mais simples (restrição disjuntiva, restrição conjuntiva, etc.) até os mais complexos (modelos de utilidade, AHP - Processo de Análise Hierárquica), são oferecidas oportunidades de uso que podem se adequar às necessidades do processo de decisão.

O item a seguir tematiza a relação entre informações subjetivas e a Contabilidade Gerencial.

\section{4 - A CONTABILIDADE GERENCIAL E AS INFORMAÇÕES SUBJETIVAS}

ludícibus (1988, p.7), ao mencionar o desafio com que a Contabilidade vem se deparando, ratifica a posição defendida, de que ela vem se esforçando a fim de que o Sistema de Informações Contábeis possa divulgar as informações realmente relevantes para os tomadores de decisão, e sustenta que "normalmente o Sistema de Informação Contábil está enfatizado com relação ao passado e não focalizado para o futuro. Para esta última hipótese ocorrer, temos que não ter receio de lidar com o julgamento, com o potencial e com o que é intangível, em lugar do verificável, realizado e tangível".

Reis \& Guerreiro (1999, p.1) aduzem que alguns estudiosos contemporâneos têm defendido a idéia de que a Contabilidade deve procurar meios de aproximar-se mais do conceito de valor, em vez de continuar ligada exclusivamente aos conceitos de custo e preço, privilegiando, neste sentido, conceitos subjetivos em detrimento da objetividade. Por outro lado, os defensores da denominada Teoria Positiva da Contabilidade ${ }^{2}$ argumentam que os conceitos contábeis não necessitam expressar aspectos subjetivos, uma vez que números contábeis, à luz da objetividade, representam importantes variáveis do processo decisório do usuário. Tais autores discutem que a consideração de conceitos subjetivos, no âmbito do sistema contábil, geralmente desperta críticas sobre a possibilidade de a contabilidade querer substituir o papel dos administradores, transferindo para o contador a 'leitura' do ambiente, o cálculo prospectivo e a interpretação dos eventos. Essa crítica não procede, pois não se pretende, enfatizando a subjetividade, transferir tais papéis para o contador.

Sveiby $(1998$, p.187) registra que a maioria das empresas avalia pelo menos alguns de seus ativos intangíveis e utiliza indicadores não-financeiros, principalmente para avaliar a eficiência operacional. As empresas do setor de produção, por exemplo, avaliam a sua produção em toneladas por hora, os hospitais e hotéis avaliam a ocupação de leitos, as escolas avaliam as notas médias dos alunos, as universidades avaliam o número de teses de doutorado por ano e assim por diante. A eficiência operacional (a eficiência da estrutura interna) é avaliada desde o início da organização industrial. Os demais ativos intangíveis começaram a ser avaliados muito mais recentemente: as estruturas externas, como as relações com os clientes, são avaliadas em forma de níveis de satisfação, enquanto a avaliação da competência é feita sob a forma de satisfação e retenção de funcionários. Mas, até agora, nenhuma das duas avaliações é monitorada com regularidade pela maioria das entidades. A dificuldade, porém, não reside em criar medidas para os intangíveis, mas, aparentemente, em interpretar os resultados.

Borgert (1999, p.53) enfatiza que a alta gerência das empresas deve se preocupar não somente com o desempenho interno mas, sobretudo, com as informações externas sobre o ambiente operacional da companhia, porque é ali o lugar da competição mercadológica e da sobrevivência das organizações. $E$ isto é diferente da perspectiva contábil tradicional de focalizar medidas internas e de caráter financeiro, como o grande objetivo da Contabilidade Gerencial, até porque as decisões, mesmo na área de custos, não são tomadas considerando-se somente uma base única de dados. Por exemplo, uma estratégia de penetração no mercado, através do lançamento de um novo produto, pode resultar, intencionalmente, em lucros baixos nos primeiros períodos. Assim, se esta

\footnotetext{
2 WATTS, Ross L. ZIMMERMAN, Jerold L. Positive accounting theory. New Jersey: Prentice Hall, 1986.
} 
estratégia for analisada em base financeira, exclusivamente, pode parecer um fracasso, sob a ótica da Contabilidade. Porém, o acesso ao mercado, o aprendizado, o reconhecimento da marca, a confiança do cliente etc, podem resultar a longo prazo, mesmo em termos financeiros, como uma decisão de sucesso.

Nesta direção, Martin (apud Beuren, 1998, p.30) explica que a informação contábil deve ser significativa para os problemas decisoriais do usuário (relevância) e não custar mais, para ser produzida, do que o valor esperado de sua utilização. Por outro lado, como uma atividade decisória específica determina as necessidades, a relevância está em direta interrelação (adaptação) com o contexto dessa decisão e com as atitudes e preferências de quem assumirá decisão.

Como forma de diminuir a subjetividade existe a possibilidade de utilização dos métodos multicriteriais de apoio à tomada de decisão, a seguir.

\section{5 - MÉTODOS MULTICRITÉRIOS DE APOIO À DECISÃO}

As teorias da metodologia Multicritério de Apoio à Decisão, conforme Borgert (1999, p.75), reconhecem a necessidade de uma abordagem mais abrangente, através da utilização de múltiplos fatores, que englobem os vários aspectos da organização, relacionados com:

- gestão: flexibilidade, rentabilidade, crescimento, adaptação, novos produtos, diversificação, redução de custos, pesquisas;

- vendas: publicidade, promoção, política comercial;

- contatos com a clientela: imagem da marca, serviços pós-venda;

- produção: produtividade, política de compras, estocagem, tecnologia, qualidade;

- competência: formação do pessoal, cultura organizacional, ambiente, motivação, responsabilidade.

Estes vários aspectos, considerados concomitantemente no processo decisório, sobretudo quando envolvem problemas de ordem estratégica, tendem a resultar em ações mais bem elaboradas, tanto aos olhos de quem decide, quanto daqueles que sofrem as conseqüências das decisões.

Freitas \& Gomes Jr. (2000, p.83) entendem que as características destes métodos normalmente incorporam:

a) a análise do processo de decisão em que essa metodologia é aplicada, sempre com o objetivo de identificar informações/regiões críticas;

b) uma melhor compreensão das dimensões do problema;

c) a possibilidade de se ter diferentes formulações válidas para o problema;

d) aceitar que, em problemas complexos, nem sempre as situações devem compulsoriamente encaixar-se dentro de um perfeito formalismo e, em particular, que estruturas que representem apenas parcialmente a comparabilidade entre as alternativas possam ser relevantes ao processo de auxílio à decisão; e

e) o uso de representações explícitas de uma estrutura de preferências, em vez de representações numéricas definidas artificialmente, pode muitas vezes ser mais apropriado a um dado problema de tomada de decisão.

Diehl (1999, p. 13) ressalta que uma questão importante na escolha da técnica mais apropriada é o número de atributos que serão levados em conta. A escolha de poucos atributos pode levar à não consideração de aspectos importantes, mesmo vitais para a análise. De outra forma, muitos atributos podem desviar a atenção dos pontos importantes, ao mesmo tempo que desperdiçam tempo e energia em pontos fúteis. Uma forma de minimizar o número de atributos é descartar aqueles nos quais as alternativas não apresentem diferenças. Outra característica que merece atenção, talvez a mais importante do ponto de vista teórico, é a independência dos atributos. Resumidamente, podese dizer que, quando a variação de um atributo não afeta outro, então eles são independentes. $\mathrm{Na}$ prática, é difícil estabelecer a relação de dependência. Normalmente, a avaliação de independência só é realizada se houver o sentimento de que a falta de independência afeta o resultado significativamente. Dessa forma, o uso de Métodos de Avaliação Multicriteriais, no processo de tomada de decisão pode ser de grande valia, permitindo a consideração tanto de aspectos objetivos, como de aspectos subjetivos.

$\mathrm{Na}$ seqüência são comentados os métodos de análise multicriterial mais conhecidos. 


\section{1 - Principais Métodos de Análise Multicriterial}

Segundo Borgert (2000, p.5), para a realização do processo de avaliação de um problema, numa abordagem multicritério, pode-se usar várias metodologias. Aponta que $\mathrm{Vincke}^{3}$ divide estas metodologias em três grandes grupos: teoria da utilidade multi-atributo, métodos de hierarquização (outranking) e métodos interativos. Por outro lado, menciona que Bana e Costa ${ }^{4}$ denomina estes métodos, respectivamente, abordagem de critério único de síntese, abordagem de subordinação de síntese e abordagem de julgamento local interativo.

Para Gomes \& Freitas Jr. (2000, p. 85), de um modo geral, problemas de decisão podem ser discretos (quando se trata de um número finito de alternativas) ou contínuos (quando tal número pode ser pensado como sendo infinitamente grande). Dentre os métodos multicritérios discretos destacam-se a Utilidade Multiatributo, o AHP (Processo de Análise Hierárquica) e os métodos Electre. Enquanto os dois primeiros são considerados os mais representativos da escola norteamericana do Apoio Multicritério à Decisão, os métodos Electre constituem o coração da chamada escola francesa. Os métodos contínuos são também denominados métodos de otimização multicritério ou métodos interativos, compreendendo basicamente métodos de programação matemática com mais de uma função objetivo. A utilização desses métodos, tanto discretos como contínuos, é imensamente facilitada através de softwares especializados.

Diehl (1997, p. 38 e segs.) menciona que existem vários métodos que podem ser agrupados e relaciona (além do Método AHP que será abordado com mais detalhes posteriormente) os seguintes:

a) Técnicas Gráficas: mesmo que não utilizem, normalmente, ponderação, são bastante úteis pois permitem a fácil visualização das situações das alternativas frente aos atributos. Podem ser indicadas, principalmente onde se requer um instrumento de uso fácil e que não requeira alto nível de acuracidade. Desta forma, é apropriada para grupos de trabalho que não possuam boa educação formal como, por exemplo, Círculos de Controle de Qualidade compostos por pessoas com baixo grau de instrução. Neste grupo incluemse as técnicas: Cartão de Escore AlternativasAtributo, Círculos Sombreados para Demonstração de Escore e os Gráficos de Estrela (Star Symbol Plot) ou Gráficos Polares.

b) Ordenação de Atributos (ou Alternativas): consistem em realizar comparações entre os atributos ou alternativas, aos pares, estabelecendo qual é preferido. No caso de não haver preferência entre um ou outro, é estabelecido o valor de $1 / 2$ preferência para ambos atributos ou alternativas. Após todas as comparações, verifica-se qual possui a maior soma de preferências. Deve-se ter atenção para garantir a consistência do julgamento, pois, assumindo transitividade de preferências, não é esperado que dois ou mais itens sejam preferidos o mesmo número de vezes, salvo em caso de empates. Se isto ocorrer, deve ser revisto o julgamento.

c) Métodos de Eliminação: são métodos usados para eliminar alternativas, através de regras de decisão. Podem estreitar o campo de alternativas ou, eventualmente, levar a uma decisão. São aplicáveis somente onde todos os atributos possuem estimativas para todas as alternativas. Além disso, os valores dos atributos devem ser escalares ou pelo menos classificados de forma ordinal. Estes métodos não consideram compensações dos atributos entre alternativas e podem ser usados onde se almeja reduzir a quantidade de alternativas. Incluem-se nesta categoria os métodos: (1) Alternativa versus Padrão, no qual a comparação é efetuada através dos atributos (existindo duas formas para este método: Restrição Disjuntiva e Restrição Conjuntiva), (2) Alternativa versus Alternativa, no qual a comparação é realizada através dos atributos (também chamado de "Método de Dominância"), e (3) Alternativa versus Alternativa, em que a comparação é feita através das alternativas (que pode ter duas formas: Eliminação Lexicográfica e Eliminação por Aspectos) além dos Gráficos de Taxas de Avaliação para Resultados de Atributos (que não é propriamente um método de decisão, mas uma ferramenta auxiliar).

\footnotetext{
${ }^{3}$ VINCKE, Philippe. Multicriteria decision-aid. J. Wiley, 1992.

${ }^{4}$ BANA E COSTA, Carlos A. Introdução geral às abordagens multicritério de apoio à tomada de decisão. Investigação Operacional, v. 66, p.117-139, jun. 1988
} 
d) Avaliação Ponderada de Alternativas: este método permite a ponderação entre as alternativas, através do estabelecimento de pesos para os atributos, de acordo com sua importância relativa. A idéia central da ponderação é estabelecer a importância relativa entre os atributos, através de pesos, partindo-se de dois pressupostos: primeiro, que é possível julgar e considerar o peso relativo de qualquer combinação de fatores, e segundo, que os pesos são considerados aditivos. Este método pode ser usado para decisões gerenciais simples, onde seja possível e desejável estabelecer-se uma quantificação dos atributos envolvidos, como por exemplo, pequenas alterações do lay-out da fábrica. Outra possibilidade é a ponderação das alternativas, na qual, após concluída a ponderação dos atributos, para cada alternativa, o atributo é confrontado com uma escala relativa, onde é avaliado em que grau ele atende à escala. Ou seja, se um atributo em questão atinge $50 \%$ do máximo esperado para ele, então, se a escala relativa for de 0 a 10 , seu escore é 5 (cinco). O procedimento é repetido até que todos os atributos, para todas as alternativas, tenham sido avaliados. Em seguida, os escores dos atributos são multiplicados pelo seu peso relativo e a alternativa que atingir a maior soma, entre todos os atributos ponderados, é a alternativa escolhida.

e) Modelos de Utilidade para Multi-atributos: as funções de utilidade são funções que associam um atributo à medida de sua importância, de acordo com o viés do decisor. Essa medida é um número entre 0 e 1 , em que o limite inferior corresponde ao pior resultado e o superior ao melhor resultado para o atributo. Através dessas funções, que não necessitam ser lineares, é possível realizar a ponderação das alternativas que indicará aquela mais consistente com os pontos de vista do decisor.

f) Programação por Objetivos (PPO ou GP - Goal Programming) é um método derivado da Programação Linear, que busca resolver problemas de alocação conflitante de recursos. Distingue-se da Programação Linear, que busca uma solução ótima, ao procurar por uma solução "satisfatória", entendida como a melhor solução possível, dentro das circunstâncias. Resumidamente, o procedimento de cálculo pressupõe que, dados os objetivos ou metas a serem buscados, a Programação por Objetivos construirá uma Função Objetivo que procurará minimizar os desvios destes objetivos.

Casarotto \& Kopittke (1998, p. 277) defendem que há três tipos principais de modelos aplicáveis para "ranquear" as alternativas: (1) Métodos Sensitivos, (2) Métodos que atendem a princípios de dominância e (3) Matriz de Ponderações. Conforme os referidos autores, tanto o método da Matriz de Ponderações como os métodos Promethee e AHP apresentam a desvantagem de a ordenação final ser expressa por um número, o que talvez não permita ao decisor captar a sutileza de pequenas variações ocasionadas por mudança de hipótese de um cenário. Assim, os chamados Métodos Sensitivos visam corrigir tal problema, baseando-se no fato de que o ser humano é analógico e que a utilização de recursos de multimídia, especialmente os visuais, pode auxiliar a tomada de decisão, notadamente em situações de multidecisor. Como exemplo de método sensitivo, os autores citam o Color Score Cards, que consiste numa matriz em que os critérios são colocados nas ordenadas, com sua importância decrescendo de cima para baixo. Nas abscissas, são colocadas as alternativas. Um conjunto de quatro cores (verde, amarelo, laranja e vermelho), que equivalem a muito bom, bom, regular e ruim, serve para avaliar as alternativas perante os critérios, podendo as cores serem atribuídas diretamente a critérios qualitativos, ou suas notas médias (em caso de votações) transformadas em cores, por uma regra, tanto para critérios quantitativos como qualitativos. O decisor escolhe alternativas com maior concentração de verdes e amarelos na parte superior da matriz ou rejeita alternativas com maior concentração de laranjas ou vermelhos em sua parte inferior. Sua principal vantagem reside na Análise de Sensibilidade altamente compreensível, pois qualquer alteração de cor será rapidamente captada, inclusive em sua intensidade.

Quanto à Matriz de Ponderações, tais autores aduzem que é a sistemática mais simples, consistindo em atribuir pesos aos diversos critérios e notas a cada alternativa, em todos os critérios. Será considerada melhor alternativa a que tiver o maior somatório de torques (pesos $x$ escores). O método possui grande simplicidade, pois é de matemática e lógica bastante simples. As desvantagens principais consistem em não haver confronto direto de alternativa a alternativa, do 
baixo significado do somatório final obtido e de que os resultados dos somatórios dos binômios "peso x nota" podem fugir à sensibilidade do decisor (pois são meramente números) e, assim, modificações sutis de resultados em análise de sensibilidade podem escapar à percepção do decisor. A análise pode ser melhorada de duas formas: acrescentando-se linhas de somatório parcial, para se ter idéia do ranking com os critérios principais e sua evolução à medida que se adicionam critérios de menor peso, e acrescentando-se uma sistemática adicional de cálculo, tornando o resultado um valor relativo, por exemplo, a 100\%. As vantagens elencadas pelos autores referidos são:

1. é totalmente transparente. Requer, como recursos matemáticos, conhecimentos das operações de multiplicação e adição apenas, podendo ser entendido em todos os seus passos por decisores sem formação matemática superior;

2. permite ampla análise de sensibilidade, sob hipóteses diferentes de desenvolvimento de cenários e sob alterações nos passos dos critérios;

3. possibilita que o próprio decisor opere o modelo, conferindo pesos aos critérios e notas às alternativas.

Relativamente aos métodos que atendem a princípios de dominância, Casarotto \& Kopittke (op. cit. p.279) argumentam que, nessa categoria, são enquadrados os métodos da escola "européia" (também conhecidos como métodos de Superação) e o método AHP (Analytical Hierarchy Process). Quanto aos métodos de Superação, estes são oriundos de pesquisas iniciadas na França e na Bélgica. O método "Promethee", desenvolvido por Brans e Vincke, em 1985, é um exemplo de método de superação, sendo adequado às situações em que os critérios possam ser representados em forma de valores. Para dada alternativa "A", sua ordenação é obtida pela classificação de seu somatório líquido, ou seja, o somatório das preferências de "A" sobre todas as demais alternativas, menos o somatório das preferências das demais alternativas sobre "A". Como vantagens do método Promethee, elencam: (a) considera as regras de dominância; (b) é de matemática simples, com lógica pouco mais complexa do que a matriz de ponderações, mas ainda assim compreensível para muitos tomadores de decisão; e (c) permite, através das funções de preferência, opções de relacionamento entre as alternativas. Em termos de desvantagens, consideram que o método Promethee é:

- idêntico ao método da Matriz de Ponderações, pois há necessidade de transformar critérios qualitativos em valores, se bem que a grande variedade de funções pode possibilitar, com algum grau de habilidade, transformar uma avaliação qualitativa em um valor;

- na análise de sensibilidade, a mudança de pontuação final derivada da alteração de uma hipótese pode não ser adequadamente percebida pelo decisor.

No tocante ao Método AHP, Ribeiro \& Costa (1999, p.7) aduzem que é uma Metodologia de Auxílio Multicritério à Decisão, proposta por Saaty no final dos anos 60 e que busca tratar de forma simples problemas de escolha complexos. Este método está baseado em três princípios do pensamento analítico: (a) construção de hierarquias (no AHP o problema é decomposto em níveis hierárquicos, como forma de buscar uma melhor compreensão e avaliação do mesmo), (b) estabelecer prioridades (o ajuste das prioridades, neste método, fundamenta-se na habilidade do ser humano de perceber o relacionamento entre objetos e situações observadas, comparando pares, à luz de um determinado foco, critério ou julgamentos paritários, e (c) consistência lógica (no AHP é possível avaliar o modelo de priorização construído em termos de sua consistência). Tais autores mencionam, também, que, na construção e utilização de um modelo de estabelecimento de prioridades fundamentado no AHP, são realizadas as seguintes etapas:

$\rightarrow$ especificação do foco principal ou objetivo geral que se espera atingir com a classificação;

$\rightarrow$ identificação do conjunto de alternativas viáveis para a priorização;

$\rightarrow$ identificação do conjunto de critérios relevantes e construção da hierarquia;

$\rightarrow$ seleção dos julgadores e definição dos métodos para a obtenção dos julgamentos paritários: é nesta etapa de julgamentos paritários que se avalia a importância de cada critério, e o desempenho de cada alternativa, à luz dos critérios;

$\rightarrow$ síntese dos dados obtidos dos julgamentos, calculando-se a prioridade de cada alternativa em relação ao foco principal; e

$\rightarrow$ análise de consistência do julgamento, identificandose o quanto o sistema de classificação é consistente na classificação das alternativas viáveis. 
Yoshitake (2000, p.4) diz que o método desenvolvido por Thomas L. Saaty incorpora critérios múltiplos na tomada de decisão. Tal processo consiste em quatro passos:

1. modelar o problema de decisão pelo seu desmembramento em uma hierarquia de elementos de decisão inter-relacionados, ou seja, critérios de decisão e alternativas de decisão;

2. desenvolver preferências por julgamento de decisões alternativas, para cada critério, e importância do julgamento do critério de decisão, através de comparação em pares;

3. calcular as prioridades relativas, para cada elemento da decisão, por meio de um conjunto de cálculos numéricos; e

4. agregar as prioridades relativas, para se chegar à classificação de prioridade das alternativas de decisão.

Ainda conforme Yoshitake (op. cit. p.5), o Método da Análise Hierárquica requer o desmembramento do complexo problema de decisão por múltiplos critérios em níveis de hierarquia. O mais alto nível corresponde ao objetivo geral do processo de decisão. O segundo nível representa o critério principal que pode, posteriormente, ser desmembrado em subcritérios no próximo nível. O último nível corresponde às alternativas de decisão.

A figura n.1 ilustra o raciocínio do método.

Figura n.1 - Representação hierárquica de um problema de decisão



Fonte: Adaptado de Casorotto \& Kopittke (1998, p. 283)

Diehl (1997, p. 66) relata que o Processo de Análise Hierárquica (AHP) é um método que pondera alternativas, partindo de um objetivo global, chamado de Foco. Através do desdobramento do Foco em Atributos ou em Sub-atributos, assim por diante, e a respectiva ponderação em cascata, as Alternativas, no nível mais abaixo, podem ser comparadas. A primeira etapa consiste na determinação da importância relativa entre atributos, entre subatributos, e assim por diante, se houver. É feita através da construção de uma matriz, na qual se define a importância do elemento x, para cada elemento do nível em questão, em relação ao elemento y. Em geral é feita uma comparação aos pares, das importâncias relativas entre os elementos em questão e, se o segundo elemento for preferido, é usado o recíproco. A segunda etapa consiste em comparar as alternativas frente a cada elemento do nível anterior (sub-atributos, se houver, ou atributos), determinando a importância relativa entre as alternativas, frente a cada elemento do nível anterior. Por exemplo, se houver sub-atributos, comparam-se as alternativas, aos pares, frente a cada sub-atributo. Após esse procedimento, a matriz obtida para cada elemento é normalizada, obtendo-se, então, os pesos relativos das alternativas. Na terceira etapa, são calculados os pesos ponderados para cada alternativa, frente aos atributos, obtendo-se os escores finais e aquela alternativa que obtiver o maior escore, será preferida.

Para Casaroto \& Kopittke (1998, p. 283), o método AHP baseia-se em três princípios: decomposição, julgamentos comparativos e síntese das prioridades. Os critérios podem ser quantitativos ou qualitativos, sem a obrigatoriedade de haver uma escala numérica, pois as comparações são feitas de forma relativa entre as alternativas. Os julgamentos comparativos entre as alternativas, para dado critério, são feitos numa escala de 1 a 9 , na qual 1 significa que as alternativas são igualmente importantes e 9 que a alternativa "A" é estritamente importante, ou seja, domina totalmente, com certeza, a alternativa " $B$ ". Reciprocamente, nesse último caso, "B" teria, em relação à "A", avaliação de 1/9. A colocação das alternativas-origem nas ordenadas e das alternativas-destino nas abscissas permite criar uma matriz de julgamentos para dado critério. A ponderação dos critérios é dada por um vetor de prioridade dos critérios. O cruzamento do Vetor Prioridade dos Critérios como Vetor Prioridade das Alternativas permite obter, para cada alternativa, o somatório dos produtos, peso (do critério) x valor (da alternativa), estabelecendo-se o ranking. A principal vantagem do método é a possibilidade de comparações relativas sem necessidade de escala absoluta para um critério, facilitando critérios qualitativos. Como desvantagens, exige operações matriciais e um conseqüente conhecimento de Álgebra Linear e o 
somatório final para a alternativa é um número cuja alteração, numa análise de sensibilidade, pode não ser adequadamente percebida.

Borgert (1999, p.65) relata que alguns pesquisadores utilizaram o método AHP também para o desenvolvimento da Contabilidade Gerencial e cita três casos como exemplo, a seguir resumidos. No primeiro caso, Chan \& Lynn (1991) aplicaram tal método para avaliação de desempenho empresarial, por considerarem que as técnicas da Contabilidade tradicional tratam as organizações como estáticas e unidimensionais, podendo ser inadequadas para avaliar desempenho em ambientes hodiernos. Tais autores preconizam a necessidade de múltiplos critérios de desempenho para a mensuração da lucratividade a longo prazo e então apresentam um modelo baseado no AHP como meio para o desenvolvimento de uma medida efetivamente abrangente. Tal modelo baseiase em múltiplos aspectos do ambiente em que é aplicado. A técnica AHP oferece meios sistemáticos para pesar múltiplas variáveis, empregando-se um processo participativo que pode melhorar a compreensão dos objetivos organizacionais. Ainda, possibilita meios para reduzir a subjetividade dos esquemas de atribuição de pesos usuais e melhora a avaliação de desempenho tanto dos segmentos da organização como dos seus gerentes. No segundo caso, Borgert menciona que Schniederjans \& Garvin (1997) aplicaram o AHP em conjunto com a programação multi-objetivo, na seleção de direcionadores de custos, para o sistema de custeio baseado em atividades. Como a metodologia ABC faz uso de múltiplos direcionadores de custos, a seleção destes pode se tornar problemática. Para tanto, tais autores usaram as duas técnicas para apoiar a definição dos direcionadores de custos e demonstraram sua aplicabilidade dentro do $A B C$, discutindo a eficácia informacional da combinação de ambas para a melhoria do sistema de custos. No terceiro caso elencado, Pamplona (1999) também usou o AHP para a seleção de direcionadores de custos, ao considerar de forma conjunta as características qualitativas, como precisão, custo do sistema e indução ao comportamento de um Sistema ABC. Após relatar os três casos, Borgert concluiu que, apesar das tentativas no desenvolvimento de modelos que ajudem no processo de melhoria das informações da Contabilidade Gerencial, observa-se que o resultado final dos trabalhos mencionados têm, como conseqüência, medidas de caráter financeiro, e que a própria sistemática AHP possui limitações.
Além dos casos mencionados, outros dois podem ser trazidos a lume.

Ribeiro \& Costa (1999), considerando os custos relativamente elevados da implementação de um sistema de custeio $A B C$ e a conseqüente inibição, para usar este sistema, por parte de pequenas e médias empresas, apresentam metodologia alternativa para alocação de custos indiretos. Tal metodologia adota as premissas básicas do ABC, integradas à utilização do AHP, propondo uma versão modificada do custeio $A B C$, na qual substitui-se o "rastreamento dos custos indiretos" pela técnica de "estabelecimento de prioridades do AHP".

No outro caso, Yoshitake (2000) preconiza uma metodologia para escolha de um Sistema de Custeio para fins de formação do preço de venda de uma organização, o qual seria oriundo tanto do modelo de análise hierárquica proposta por Saaty, quanto do ajustamento próprio a uma entidade que tenha de: (a) implantar um sistema de custeio que the proporcione informações para a tomada de decisões na formação de preços; (b) informar quais aspectos são mais ou menos cruciais para uma dada política estratégica de preços da organização;e (c) alterar as ponderações de dirigentes ou de contextos, como replanejar, rapidamente, uma política de preços já em execução. Ou seja, o sistema de custeio será uma ampla ferramenta de trabalho, ajustada a contextos, ou facilmente alterável de acordo com diferentes propósitos.

\section{6 - CONSIDERAÇÕES FINAIS}

O uso de conceitos subjetivos afeta, de maneira drástica, o aspecto da objetividade, ferozmente defendido por muitos teóricos da contabilidade, preocupados com a sua utilização por usuários externos. Entretanto, a utilidade da informação contábil deve prevalecer sobre a sua objetividade, sob o ponto de vista das necessidades dos usuários internos, notadamente os gestores.

Os métodos multicritérios agregam um valor significativo à informação contábil, na medida em que não somente permitem a abordagem de problemas considerados complexos e, por isto mesmo, não tratáveis pelos procedimentos intuitivo-empíricos usuais, mas também conferem ao processo de tomada de decisão uma clareza e conseqüente transparência, não disponíveis quando esses procedimentos ou outros métodos de natureza monocritério são utilizados. 
$\mathrm{Na}$ área contábil, porém, a aplicação dos métodos multicritérios é ainda muito escassa. Cabe, portanto, aos profissionais da Contabilidade, inteirarem-se acerca das características dos métodos e suas prováveis aplicabilidades na lide gerencial cotidiana, para usufruir desta poderosa ferramenta de apoio ao processo de tomada de decisões.

\section{REFERÊNCIAS BIBLIOGRÁFICAS}

ATKINSON, Anthony A. Et alii. Contabilidade Gerencial. São Paulo : Atlas, 2000.

BANA E COSTA, Carlos A. Introdução geral às abordagens multicritério de apoio à tomada de decisão. Investigação Operacional, v. 66, p.117-139, jun. 1988.

BEUREN, Ilse M. Gerenciamento da informação. São Paulo: Atlas, 1998.

BORGERT, Altair. Construção de um sistema de gestão de produtos à luz de uma metodologia construtivista multicritério. UFSC: Florianópolis, 1999. Tese (doutorado).

BORGERT, Altair. O processo de avaliação em gestão contábil multicritério: a construção da função de valor. In: Congresso Brasileiro de Custos, 7, 2000, Recife, Anais... Recife:

UFPE, 2000. CD-ROOM.

CANADA, J. R. SULLIVAN, W. G. Economic and multiatributte evaluation of advanced manufacturing systems. Englewood Cliffs: Prentice-Hall, 1989.

CASAROTTO FILHO, Nelson. KOPITTKE, Bruno Hartmut. Análise de investimentos. São Paulo: Atlas, 1998.

CHAN, Yee-Ching Lilian and LYNN, Bernadette Eleanor. Performance evaluation and the Analytic Hierarchy Process. Journal of Management Accounting Research, Florida, v.3, p.57-87, 1991.

COSTA, José Fabiano da Serra. Uma aplicação de metodologia multicritério na qualidade do ensino. In: Encontro Nacional de Engenharia de Produção, 19, 1999, Rio de Janeiro,

$$
\text { Anais... UFRJ, 1999. CD-ROOM. }
$$

DIEHL, Carlos Alberto. Proposta de um sistema de avaliação de custos intangíveis. UFRGS: Porto Alegre, 1997, Dissertação (mestrado).

DIEHL, Carlos Alberto. Custos intangíveis: uma proposta de avaliação. In: Congresso Brasileiro de Custos, 6, 1999, São Paulo, Anais... São Paulo: FIPECAFI, 1999. CD- ROOM.

GOMES, Luiz F. A. M. FREITAS JR, Antonio A. A importância do apoio multicritério à decisão na formação do administrador. Revista ANGRAD, v.1, n.1. Rio de Janeiro, jul./set.2000

IUDíCIBUS, Sérgio de . A contabilidade como sistema de informação empresarial. Boletim do IBRACON, n.245, p.7-9, out./nov. de 1988.

JOHNSON, H Thomas. KAPLAN, Robert S. Contabilidade gerencial: a restauração da relevância da contabilidade gerencial nas empresas. Rio de Janeiro: Campus, 1993.

OSTRENGA, Michael R. Et alii. Guia da Ernst \& Young para gestão total dos custos. Rio de Janeiro: Record. 1993.

PAMPLONA, Edson de Oliveira. Avaliação qualitativa de cost drivers pelo método AHP. In: Congresso Brasileiro de Custos, 6, 1999, São Paulo, Anais... São Paulo: FIPECAFI, 1999. CD-ROOM.

REIS, Ernando A. dos. GUERREIRO, Reinaldo. O papel da subjetividade no contexto da contabilidade gerencial. In: Congresso Brasileiro de Custos, 6, 1999, São Paulo, Anais... São Paulo: FIPECAFI, 1999. CD-ROOM.

RIBEIRO, Alcimar das Chagas e COSTA, Helder Gomes. Emprego do método de análise hierárquica (AHP) na distribuição de custos indiretos: uma proposta para a pequena e média empresa. In: Encontro Nacional de Engenharia de Produção, 19, 1999, Rio de Janeiro, Anais... UFRJ, 1999. CDROOM.

SCHNIEDERJANS, Marc J. e GARVIN, Tim. Using the analytic hierarchy process and multi-objeticve programming for the selection of cost drivers in activity-based costing. European Journal of Operational Research, Amsterdan, v. 100, n.1, p.7280, jul. 1997.

SVEIBY, Karl Erik. A nova riqueza das organizações. Rio de Janeiro: Campus, 1998.

VINCKE, Philippe. Multicriteria decision-aid. J. Wiley, 1992.

WATTS, Ross L. ZIMMERMAN, Jerold L. Positive accounting theory. New Jersey: Prentice Hall, 1986.

YOSHITAKE, Mariano. Análise de decisões em custos com o uso da metodologia de análise hierárquica. In: Congresso Brasileiro de Custos, 7, 2000, Recife, Anais... Recife: UFPE, 2000. CD-ROOM. 